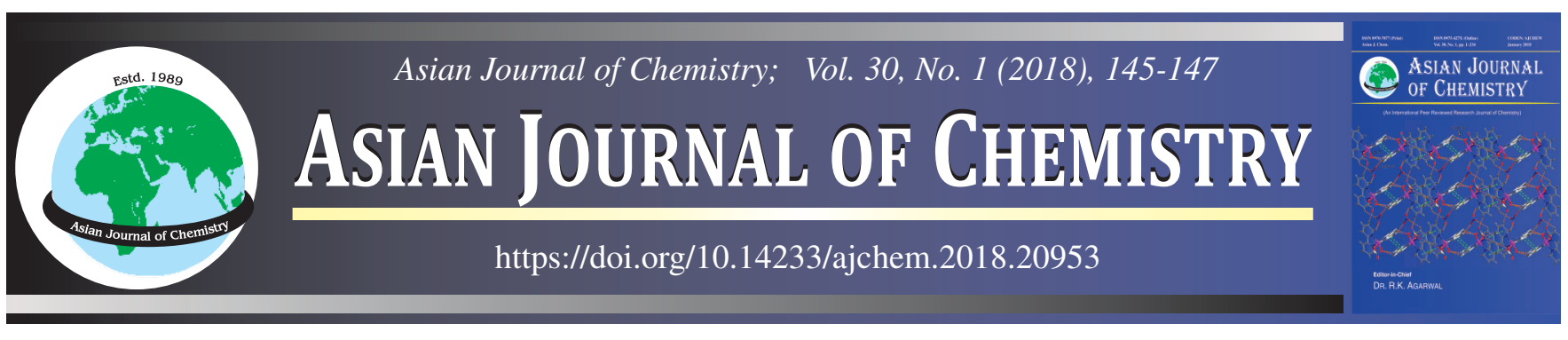

\title{
Poly(Lactic Acid) Packaging Modified Curcumin as Bioactive Substance in Tea Drink (Camelia sinensis)
}

\author{
Hanafi $^{1}$, Septilina Melati Sirait ${ }^{1, *}$, Candra Irawan ${ }^{2}$ and Henny RochaenI ${ }^{2}$
}

${ }^{1}$ Department of Quality Assurance of Food Industry, Polytechnic of AKA Bogor, Bogor 16158, Indonesia

${ }^{2}$ Department of Chemical Analysis, Polytechnic of AKA Bogor, Bogor 16158, Indonesia

*Corresponding author: Fax: +62 251 8650352; Tel: +62 251 8650351; E-mail: septilinamelati.aka@ gmail.com

The addition of curcumin with $0.5 \%$ concentration resulted in poly(lactic acid) (PLA) packaging with the best antioxidant and antimicrobial activity was $\mathrm{IC}_{50}=0.83 \%$. Antimicrobial showed positive inhibiting $E$. coli and B. cereus bacteria despite weak activity. The study of modified poly(lactic acid) packaging of curcumin in tea drink was better than commercial plastic packaging which carried out for 7 days. Antioxidant activity was $\mathrm{IC}_{50}=4.37-16.36 \%$ on the modified poly(lactic acid) curcumin packaging and antioxidant activity on commercial plastic was $\mathrm{IC}_{50}=4.37-20.21 \%$. The increasing of total microbial log was lower (2.2-4.39) than commercial plastic (3.24-5.82) and total phenol reduction of $0.5 \%$ was lower than commercial plastic packaging dropped by $0.0625 \%$.

Keywords: Curcumin, Poly(lactic acid) (PLA), Antioxidant, Antimicrobe.

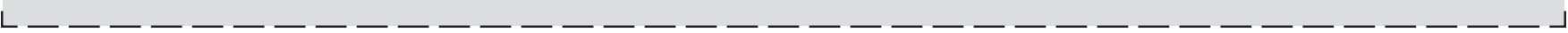

\section{INTRODUCTION}

Biodegradable plastic can be made from natural polymers, one of which was starch. The plastic was known as poly(lactic acid) (PLA). Poly(lactic acid) is a polymer from renewable sources and derived from lactic acid esterification process from fermentation of bacteria by using starch substrate or simple sugar. Poly(lactic acid) has a heat resistance, strong and elastic polymer [1]. Poly(lactic acid) packaging can be used to package various foodstuff, one of which was tea drink. To improve the function of PLA packaging in maintaining the quality of tea drink, was adding bioactive substances such as curcumin which had antioxidant and antimicrobial activity. Antioxidant was defined as a compound which can delay, making slower and prevent the oxidation process, whereas antimicrobial is a compound which can kill or inhibit the growth of microorganism [2].

The addition of curcumin in the manufacture of PLA packaging aimed to prolong the shelf life which considering the active compound of tea leave, such as phenol was easily oxidized and covered microbes on period of storage. The addition of curcumin as a bioactive substance (antioxidant and antimicrobial) on PLA packaging was expected to maintain the quality of tea drink, so the benefit for the health of body remained function properly. The objective of this research was aimed to develop PLA food packaging which modified bioactive substance curcumin as biodegradable packaging material to prevent tea drink from the damage during the storage.

\section{EXPERIMENTAL}

Packaging of poly(lactic acid)-curcumin: Weighed $5 \mathrm{~g}$ of PLA, $3.5 \mathrm{~g}$ of montmorilonite (MMT) and curcumin with weight adjusted for treatment $(0.05,0.25,0.5$ and $1 \mathrm{~g})$. Further prepared a solution of chloroform as much as $100 \mathrm{~mL}$ in a glass cup and heat at a temperature of $70^{\circ} \mathrm{C}$ using a hot plate while stirring using a magnetic stirer with a speed of $750 \mathrm{rpm}$. In the first 15 min added PLA, the second 15 min added MMT, the third 15 min added curcumin according to treatment and the fourth $15 \mathrm{~min}$ added $0.5 \mathrm{~mL}$ of polyethylene glycol (PEG) 400. Then the heating was continued, so the total heating time was $1.5 \mathrm{~h}$. Then the solution was poured into a petri dish and allowed to cool and harden at room temperature so as to produce PLA-curcumin packaging.

Making drink tea: One bag of black tea dipped in 500 $\mathrm{mL}$ hot water with temperature $60-70{ }^{\circ} \mathrm{C}$, then added sugar with concentration $10-15 \%$ (w/v) and stirred homogeneously. The tea drink was put in a sterile bottle and sterilized by autoclave at $121^{\circ} \mathrm{C}$ for $15 \mathrm{~min}$. The tea was ready to be used in the research.

Antioxidant activity: Antioxidant activity was measured by radical scavenger method [3]. Each of the sample was pipetted $5 \mathrm{~mL}$ into $100 \mathrm{~mL}$ flask and then diluted using $95 \%$ ethanol. Then homogenized to obtain $5 \%$ solution. Afterwards, the solution was filtered using filter paper to obtain a clear purple solution. Each sample $0.1 \mathrm{~mL}$ added DPPH $(400 \mu \mathrm{L}$ in 
ethanol) and $3 \mathrm{~mL}$ of $95 \%$ ethanol. After that, the mixture was vortexred and measured the absorbance at 0, 5, 10, 15, 20 min using UV-visible at $517 \mathrm{~nm}$.

$$
\text { Scavenger }(\%)=\frac{\left(A_{0}-A_{t}\right)}{N_{0}} \times 100
$$

where: $\mathrm{A}_{0}=$ Absorbance of DPPH solution; $\mathrm{A}_{\mathrm{t}}=$ Absorbance of test reference sample.

Then, made linear curve between sample concentration $(\mathrm{X})$ and $\%$ inhibition $(\mathrm{Y})$ so that the equation:

$$
\begin{gathered}
\mathrm{Y}=\mathrm{aX}+\mathrm{b} \\
\mathrm{IC}_{50}(\mathrm{ppm})=\frac{50-\mathrm{b}}{\mathrm{a}}
\end{gathered}
$$

Antimicrobial activity : $200 \mu \mathrm{L}$ suspension of bacteria (E. coli and B. cereus) was added to Nutrient agar and then spread using $o s e$. For the media of antifungi used PDA (potatos dextrose agar) and test fungus Pestalutiopsis, Penicilium and A. niger. And then put a piece of sterile tracing paper $(6 \mathrm{~mm}$ diameter discs) on the surface of the PDA which had previously been immersed in test solution (xantorizol and xantorizol dimerization) for $30 \mathrm{~min}$. The incubation process was done at $37^{\circ} \mathrm{C}$ for $24 \mathrm{~h}$. Observations were made by measuring the zone of resistance formed around the disc paper as a pellucid zone using a ruler and then written [4].

Zone of inhibition $=$ Diameter $($ pellucid zone + disc $)-$

$$
\text { Diameter of disc paper }
$$

Determination of total phenol: Determination of the total phenol was done based on the Folin-Ciocalteu method. The tea drink was filtered using filter paper, then $1 \mathrm{~mL}$ filtrate was pippetted into a $10 \mathrm{~mL}$ measuring flask and added with $0.8 \mathrm{~mL}$ of folin reagent. After that, the mixture was shaken. Furthermore, $5 \% \mathrm{Na}_{2} \mathrm{CO}_{3}$ was added until the boundary marks, so the total volume of the solution becomes $10 \mathrm{~mL}$. The solution was allowed to stand for $60 \mathrm{~min}$ and the absorption was measured at a maximum wavelength of $750 \mathrm{~nm}$. The measurement was repeated 3 times. The concentration of phenolic compounds in the sample can be determined by passing the sample absorbance on the calibration curve [5].

Total microbial analysis of TPC method: $1 \mathrm{~mL}$ of each sample was pippetted into the aseptically labeled sterile Petri dish. Each petri dish containing the sample was filled with 12-15 mL of PCA (plate count agar) liquid $40-45^{\circ} \mathrm{C}$ and homogenized. Therefore, the blank was done. Agar medium was let to be freezed. Then incubated at $37{ }^{\circ} \mathrm{C}$ incubator in a position reversed for $2 \times 24 \mathrm{~h}$ and observed. The number of growing microbes was calculated using a colony counter and expressed as total colony/mL sample [6].

\section{RESULTS AND DISCUSSION}

Manufacture of modified poly(lactic acid) packing curcumin: The addition of curcumin in the range of 0.05 , $0.25,0.5 \%$ from $1 \%$ of the total volume. The PLA packaging formula with $0.5 \%$ addition of curcumin has the lowest $\mathrm{IC}_{50}$ (or the highest antioxidant activity with $\mathrm{IC}_{50} 0.83 \%$ ). The decrease in activity can be caused by antioxidant compound reacted with the component of PLA causing the number of compound which made oxidized free radicals was smaller (Fig. 1) [7]. The optimum value of $\mathrm{IC}_{50}$ on the addition of $0.5 \%$ curcumin concentration was used as the optimum curcumin concentration for subsequent research.

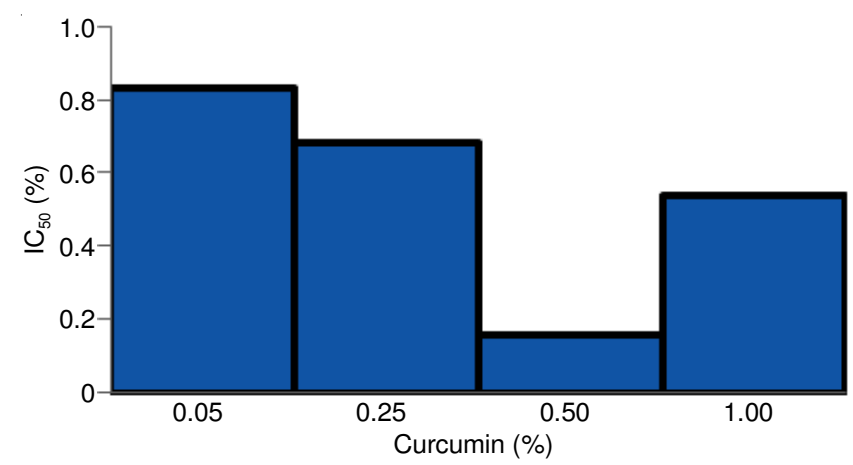

Fig. 1. Antioxidant activity on poly(lactic acid) packaging at various formulation of curcumin addition

Poly(lactic acid) packaging was not significantly affect the Gram-positive and Gram-negative bacterial inhibition, although there is a clear zone in the addition of $0.05 \%$ curcumin for both types of bacteria (E. coli and B. cereus). This indicates that curcumin inhibition applied to the PLA packaging is very weak against the growth of E. coli and B. cereus (Table-1).

\begin{tabular}{ccc}
\multicolumn{3}{c}{ TABLE-1 } \\
INHIBITION OF MODIFIED PACKAGING \\
PLA AGAINST E. coli AND B. cereus \\
\hline $\begin{array}{c}\text { Formula of PLA packaging in } \\
\text { adding curcumin }(\%)\end{array}$ & \multicolumn{2}{c}{ Inhibitory $(\mathrm{mm})$} \\
\cline { 2 - 3 } . $\%$ coli & B. cereus \\
\hline 0.05 & 1.0 & 2.0 \\
0.25 & - & - \\
0.50 & 0.6 & - \\
1.00 & - & - \\
\hline
\end{tabular}

Curcumin is a natural compound that can inhibit Grampositive and weak against Gram-negative, but curcumin easily damaged by temperature and light. The manufacture of PLA packaging was using temperature $70^{\circ} \mathrm{C}$, so it is suspected that the active nature of curcumin inhibiting bacteria was not work optimally. Curcumin is a phenolic compound which can also inhibit bacterial growth by denaturing and destroying the cell membrane so that the cell metabolism process will be disrupted [8]. Curcumin derived from turmeric has a broad spectrum antibacterial activity which active against various types of Gram-positive and Gram-negative.

The difficulty of antibacterial substances in the modified packing of curcumin to penetrate the sterol membrane on the fungus wall causing the growth of Pestalutiopsis, Penicilium and Aspergillus niger can not be inhibited.

Antioxidant for tea drink during storage: Modified PLA packaging of curcumin has the ability to inhibit damage of tea drinks for 7 days storage. This can be seen from the low value of $\mathrm{IC}_{50}$ which indicated high antioxidant and relatively stable during storage compared to commercial plastics. The antioxidant activity $\left(\mathrm{IC}_{50}\right)$ of the tea drink in the modified PLA curcumin (both cold and room temperature) was in the range of $4.37-16.36 \%$, while in commercial plastic was in the range of $4.37-20.21 \%$. 
Tea drink stored on commercial plastic had higher damage than tea drink stored on modified PLA packages of curcumin. It can be seen from the significant increasing of $\mathrm{IC}_{50}$ which packed of commercial plastic was from 4.37 to $20.21 \%$ on the second day. In the subsequent storage, at the $4^{\text {th }}$ day to $7^{\text {th }}$ day was not changes significantly which indicated the destruction of antioxidant compound of tea drink at $2^{\text {nd }}$ day. According to this case, the modification in addition of curcumin on PLA packaging can be an alternative to maintain the quality of tea drink during storage [9].

Total tea microbial test during storage: The increasing of microbial total tea drink packed and stored at cold temperature tends to be slower than tea drinks stored at room temperature [10]. At cold temperature for 7 days, tea drink has log of microbial 1.72-3.24 while at room temperature total log microbe reach 5.82 (Fig. 2). It can be caused by room temperature which were more likely for growing microbe than at cold temperature [11]. The growth of almost all microorganism still grew more slowly at temperature $0-5^{\circ} \mathrm{C}$ inside the refrigerator than at room temperature $20-45^{\circ} \mathrm{C}$.

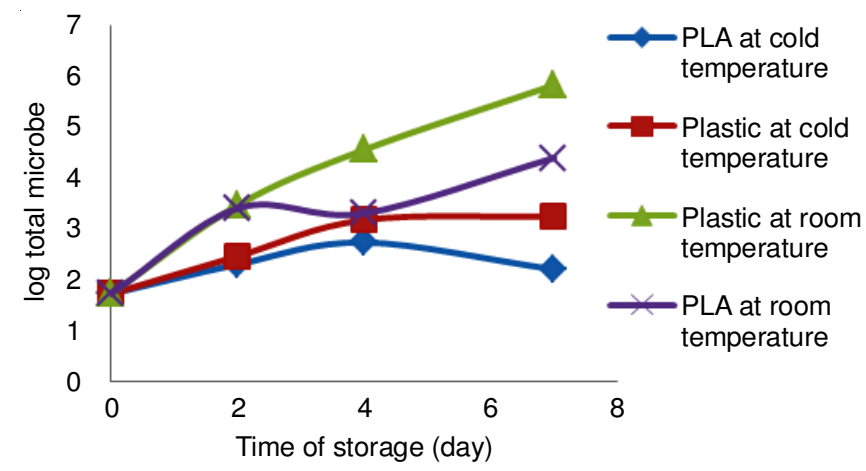

Fig. 2. Total log microbial tea drink saved at packaging during storage

Total tea phenol test during storage: The phenol level of tea drink at the beginning of storage was $0.09 \%$, then decreased to $0.025-0.04 \%$ on the $7^{\text {th }}$ day (Fig. 3). The damage of phenol compounds can be caused by enzymatic browning reaction, was a changing of phenolic compound of the quinol to quinone compound [12].

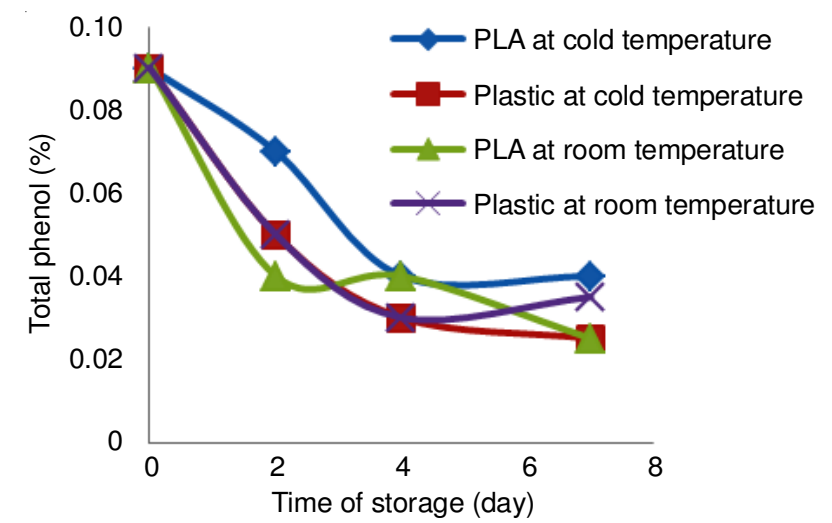

Fig. 3. Total phenol level (\%) black tea drink packed and stored with curcumin modified PLA at cold and room temperature
Curcumin modified PLA packaging was expected to prevent oxidation reaction, so that the decreasing in total phenol during storage was lower (down $0.5 \%$ ) than control packaging (commercial plastic) down by $0.0625 \%$. In general, the ability of all packages to prevent the damage of phenol was almost the same. This was presumed from the length of storage which has not reached the extreme time for total decline of phenol.

\section{Conclusion}

Based on this research, it can be concluded that the study of modified PLA packaging of curcumin in tea drink was better than commercial plastic packaging. Antioxidant activity was $\mathrm{IC}_{50}=4.37-16.36 \%$ on the modified PLA curcumin packaging and antioxidant activity on commercial plastic was $\mathrm{IC}_{50}=4.37$ $20.21 \%$. The increasing of total microbial log was lower (2.24.39) than commercial plastic (3.24-5.82) and total phenol reduction of $0.5 \%$ was lower than commercial plastic packaging dropped by $0.0625 \%$.

\section{ACKNOWLEDGEMENTS}

The authors acknowledge the kindness and cooperation of the informants and local administrators in the study area and the support from Polytechnic of AKA Bogor.

\section{REFERENCES}

1. I.S.M.A. Tawakkal, M.J. Cran, J. Miltz and S.W. Bigger, J. Food Sci., 79, R1477 (2014);

https://doi.org/10.1111/1750-3841.12534.

2. C. Bastioli, Macromol. Symp., 135, 193 (1998); https://doi.org/10.1002/masy.19981350122.

3. M. Elmastas, I. Gülcin, Ö. Isildak, Ö.I. Küfrevioglu, K. Ibaoglu and H.Y. Aboul-Enein, J. Iran. Chem. Soc., 3, 258 (2006); https://doi.org/10.1007/BF03247217.

4. W. Mangunwardoto, Deasywaty and T. Usia, Int. J. Basic Appl. Sci., 12, 69 (2012).

5. N. Gheldof and N.J. Engeseth, J. Agric. Food Chem., 50, 3050 (2002); https://doi.org/10.1021/jf0114637.

6. S. Fardiaz, Food Microbiology, Food Technology and Nutrition Division, Faculty of Agricultural Technology, Institut Pertanian, Bogor Indonesia (1990).

7. S.M. Sirait and Hanafi, WARTA AKAB, 37, 43 (2017)

8. S. Cikrici, E. Mozioglu and H. Yilmaz, Rec. Nat. Prod., 2, 19 (2008).

9. N.E. Suyatma, A. Copinet, V. Coma and F. Fricoteaux, J. Appl. Polym. Sci., 117, 3083 (2010); https://doi.org/10.1002/app.32115.

10. P.M. Gaman and K.B. Sherrington. Introduction of Food Science Nutrition and Microbiology, Gadjah Mada University Press, Yogyakarta (1992).

11. S.P. Santoso, Fresh Preserving Materials Technology. Malang: Naskah Publikasi Uwiga (2006).

12. F.G. Winarno, Food Chemistry and Nutrition. Jakarta: Mbrio (2002) 